Meta

Journal des tradlucteurs

Translators' Journal

\title{
L'auteur de l'initiation à la Transatlantique (en préparation) répond
}

\section{Irène V. Spilka}

Volume 22, numéro 1, mars 1977

Histoire de la traduction au Canada

URI : https://id.erudit.org/iderudit/004206ar

DOI : https://doi.org/10.7202/004206ar

Aller au sommaire du numéro

Éditeur(s)

Les Presses de l'Université de Montréal

ISSN

0026-0452 (imprimé)

1492-1421 (numérique)

Découvrir la revue

Citer ce document

Spilka, I. V. (1977). L'auteur de l'initiation à la Transatlantique (en préparation) répond. Meta, 22(1), 92-92. https://doi.org/10.7202/004206ar d'utilisation que vous pouvez consulter en ligne.

https://apropos.erudit.org/fr/usagers/politique-dutilisation/ 


\section{L'AUTEUR DE L'INITIATION A LA TRANSLATIQUE (EN PRÉPARA- TION) REPOND}

Translatique n'est pas, comme le croit mon collègue Brian Harris, un mot portemanteau. En voici l'histoire. Voulant donner un nom à la théorie de la traduction j'hésitais entre traductiologie et traductologie, et je fis part de ma perplexité à Jean Hesse, dont la vaste culture linguistique m'inspire beaucoup d'estime et d'admiration. C'est lui qui me proposa translatique, formé à partir de l'ancien français translater ${ }^{1}$ et du suffixe ique, que l'on retrouve dans tant de mots bien français comme mathématique, logique, stylistique, informatique. Ce terme me parut particulièrement heureux, car il rejoignait celui de translateur proposé par Felix Kahn pour englober traducteur et interprète lorsqu'il s'avère souhaitable de les désigner par un collectif (voir : "Traduction et linguistique »dans les Cahiers Ferdinand de Saussure, 27 (1971-1972) : 21-42). Il a cependant un autre mérite, c'est celui de permetíre la formation d'un dérivé qui souligne la différence entre le praticien et le théoricien à l'aide d'un couple de mots issus d'une même racine : translateur et translaticien se complètent en s'opposant, ce qui est dans la plus pure tradition de la linguistique structurale.

Je tiens en terminant à remercier M. Harris de m'avoir fourni l'occasion de cette mise au point qui, bien sûr, n'empêchera pas les esprits caustiques d'ironiser.

IRÈNE V. SPILKA

1. Dictionnaire de l'ancien français jusqu'au milieu du xrve siècle, par A.J. Greimas, Paris, Larousse, 1968, p. 637 : translater v. (déb. XII e s., Ps. Cambr.; dér. verb. de translatum, p. passé de transferre). ... $2^{\circ}$ Traduire. 